\title{
Did we Eradicate SARS? Lessons Learned and the Way Forward
}

\author{
Robert Smith* \\ Department of Mathematics and Faculty of Medicine, The University of Ottawa, Canada \\ *Corresponding author: Robert Smith?, Department of Mathematics and Faculty of Medicine, The University of Ottawa, Canada. \\ To Cite This Article: Robert Smith?.Did we Eradicate SARS? Lessons Learned and the Way Forward. Am J Biomed Sci \& Res. 2019 - 6(2). AJBSR. \\ MS.ID.001017. DOI: 10.34297/AJBSR.2019.06.001017.
}

Received: 紫 October 04, 2019; Published: 此 November 15, 2019

\begin{abstract}
The 2003 SARS outbreak is examined and the various human-derived responses to it evaluated. The arguments for and against eradication are presented and compared to similar efforts with other diseases, both successful and not, in order to determine whether we should add SARS to the list of eradicated diseases.
\end{abstract}

\section{Introduction}

Eradication of an infectious disease is defined as:

"Permanent reduction to zero of the worldwide incidences of infection caused by a specific agent as a result of deliberate efforts: intervention measures are no longer needed" [1]. As epidemics recede, investment of time, money and resources are often reduced, with results dependent on the level of control adopted by the country that undertakes the least control [2]. Misunderstanding of eradication criteria has led to neglect or complete cessation of intervention activities-with concurrent decrease in financial resources-and thus to re-emergence of the target disease [3]. Despite strong biological, technical and cost-benefit arguments for infectious-disease eradication, securing societal and political commitments is often a substantial challenge [4] (Table 1).

\begin{tabular}{|c|c|}
\hline Table 1: Disease-eradication overview. & Biological and Technical Feasibility; \\
\hline Criteria & $\begin{array}{c}\text { Costs and benefits; } \\
\text { S }\end{array}$ \\
\hline Successes & Societal and Political Considerations [4] \\
\hline Candidates for Eradication Last Century & Smallpox (1980), Rinderpest (2011) [4,5] \\
\hline Reasons for Failure & Malaria, Yaws, Yellow Fever [4] \\
\hline Current Eradication Programs & Mismanaged Strategies, Animal Reservoirs [4] \\
\hline Biologically/Technically Feasible Candidates & Poliomyelitis [6], Leprosy [7], Guinea-worm Disease [8] \\
\hline
\end{tabular}

A critical tool for smallpox eradication, in addition to an extremely effective vaccine, was photographic disease-recognition cards [10], demonstrating that non-biomedical interventions were also important. Barriers to smallpox eradication included cultural traditions, a lack of societal support and religious beliefs [4]. Guinea worm disease is likely to be the first disease eradicated without a vaccine, treatment or immunity, using behavior changes alone, coordinated through public-private partnerships [8]. Our record of tackling new diseases is poor. In the late twentieth century, HIV/ AIDS spread from a few early cases to a global pandemic [11]. Malaria rebounded from a global low in the 1970 s to become a re-emerging disease in the developing world [12]. In 1999, West Nile Virus crossed continents, establishing itself as a recurrent and chronic infection, resulting in significantly larger neuroinvasive 
epidemics in the new world, compared to the old world [13]. Multiple non-vaccination control measures have been implemented against these and other emerging or re-emerging diseases, without hope of eradication. So, what makes SARS different? Controlling the course of SARS in China and elsewhere was the result of rapid and unprecedented multisectoral preparedness and outbreak response activities by national authorities [14]. Vietnam's decision to tackle SARS openly and decisively, despite risks to its image and economy, has been praised as a success story that put public health before politics, averting a potentially catastrophic result [15]. Real-time information was used for evidence-based control, allowing the World Health Organization (WHO) to alert hospitals, airlines and airports of the disease, and they were able to provide specific guidance to health workers on clinical management and protective measures to prevent further nosocomial spread [16]. With no new cases in over a decade, the time has come to decide whether we should take credit for its eradication (Table 2).

Table 2: SARS overview.

\begin{tabular}{|c|c|}
\hline Table 2: SARS overview. & China [17] \\
\hline Origins & Hong Kong, Taiwan, Singapore, Canada [18,19] \\
\hline Countries with major outbreaks & November 2002 to July 2003 [20] \\
\hline Major Timeline & 2004 (laboratory- and animal-derived) [21] \\
\hline Subsequent cases & Fever, mild respiratory symptoms, pneumonia [17] \\
\hline Symptoms & 8096 cases, 774 deaths, 29 countries [20] \\
\hline Disease burden & Personal protection, isolation [18], airport screening [16] \\
\hline Control & No \\
\hline Vaccine developed? & No \\
\hline Cure? & \\
\hline
\end{tabular}

\section{The Case for SARS Eradication}

Our model for successful eradications comes down to two data points: smallpox and the veterinary disease rinderpest. Both were reliant on the development of a successful vaccine. Expanding our list either now or in the future will almost certainly mean expanding eradication techniques to include non-vaccination-based methods such as education, behavior changes and bureaucratic regulation. When Guinea-worm disease is eradicated in the next few years, this may shift our thinking from a vaccination-based strategy of eradication to a broader set of tools that can be successfully used to tackle infectious diseases. New technology has the potential to play a large role in the control and eradication of future diseases. Ventilators that breathe for a patient while their lungs repair were used in both SARS and the 2009 H1N1 pandemic, saving lives that would have been lost in the 1918 H1N1 outbreak [22,23]. Temperature monitors at airports played a role in monitoring the SARS outbreak and were used again in the 2014 Ebola epidemic $[24,25]$. While vaccines are undoubtedly a public-health success story, eradication of future diseases will be slow unless other tools can be developed and harnessed. Mathematical models are already using the SARS case as a motivating example for successful intervention strategies, illustrating that multiple intervention strategies are required, that school closures, contact tracing and quarantine are effective tools and that delays between the onset of symptoms and hospitalization are critical and can be reduced when health workers and the public are alert [26]. Lessons from SARS have informed response strategies to new diseases such as Middle East Respiratory Syndrome [27] or calls for more government openness and transparency in identifying new outbreaks [21]. Having SARS as a clear example of a success story allows general principles about disease control to be explored and future-planning for potential outbreaks to have stronger arguments. Furthermore, the psychological implications of adding to our meagre list of eradication success stories should not be undervalued. Public trust in regulating authorities is not high, as myths about vaccines and autism demonstrate. Being able to demonstrate clearly and unambiguously that regulatory action has resulted in the eradication of multiple human diseases is a powerful argument for more action in the future that may save a great many lives.

\section{The Case Against SARS Eradication}

The strongest argument against claiming credit for eradication is that we simply got lucky. SARS is transmitted by droplets during close person-to-person contact and was not transmitted with the same facility as influenza and other infections that are airborne; furthermore, SARS did not spread to developing countries where surveillance systems were not sensitive enough to detect its presence before it had spread widely [16]. New diseases with few cases are subject to stochastic effects, which can result in arbitrary elimination [28]. So perhaps the disease vanished by chance and our control efforts made little to no difference. For example, in 1976, an outbreak of swine flu (H1N1) caused the Ford administration to undertake mass vaccinations, with approximately $25 \%$ of the US population vaccinated. Whereas the disease killed a single soldier, 25 people died from the vaccine. The Ford administration was criticized for wasting resources and promoting panic. However, this decision has been viewed with mixed results in hindsight, with 
previous detractors subsequently claiming that it was an example of public-health bureaucracy at its finest [29]. It's unknown whether this public-health mobilization served to ward off the outbreak or whether the disease vanished on its own. H1N1 was of course not eradicated and remains circulating at low levels. Another possibility is that the seasonality of the disease played a role. The bulk of SARS infections occurred in the northern winter, with few cases occurring in the summer. So perhaps eradication of SARS was simply because it got warmer? However, this ignores the fact that a great many seasonal diseases persist from year to year. Global travel between hemispheres can also rapidly transfer diseases between seasons, as happened with SARS [30].

Eradicating respiratory diseases is difficult. They may rebound after a quiescent period, as many diseases do [31]. The notion of eradication is difficult to apply to emerging zoonotic diseases. The WHO's consensus document on the epidemiology of SARS, published during the pandemic in 2003, stated "The eradication of SARS-CoV is unlikely if infection is zoonotic" [32], which was later found to be the case. Evolution has had time to generate variants in SARS CoV's wildlife hosts during the past 13 years, so we may see a related virus emerge in the next decade or century. If we declare eradication, we run the risk of SARS someday re-emerging under similar conditions that gave rise to it originally, which has the potential to psychologically undercut any claim of eradication.

\section{The Verdict}

While concerns about the re-emergence of SARS from animal sources are valid, there is still place for a more nuanced verdict for the specific outbreak: namely, that the 2003 SARS epidemic was permanently reduced to zero as a result of deliberate efforts, requiring no further intervention methods. This is precisely the definition of eradication.

SARS demonstrated some of the positive features of a globalized society: the advantages that rapid electronic communications and new information technologies bring in responding to emergencies and the willingness of the international community to form a united front against a shared threat [16]. So, if global interconnectedness of cities facilitated the initial worldwide spread of SARS, it also played a role in its elimination. We should not undervalue our collective role in this-or the role that we may play in the control of future pandemics.

It is long past time that we declared the 2003 SARS epidemic to have been successfully eradicated through human intervention. The psychological impact of such a declaration is enormous, with the potential to assist future disease eradication efforts. Psychology aside, the strongest argument for the eradication of the 2003 SARS epidemic is fundamentally that it appeared, we acted, and it is gone. Whether this is correlation or causation may never be fully known, but the outcome surely plays a large role in the final assessment. Given that government and bureaucratic institutions often shoulder the blame for pandemics that were not controlled, without consideration as to whether they could have been, it seems only fair to give credit for one where the outcome was positive. In many ways, the 2003 SARS epidemic was an easy disease to eradicate. Hospital access could be restricted, masks issued, borders monitored, airports screened. Nevertheless, the fact that these steps were undertaken at all, and successfully, should not be minimized. If the biggest argument against declaring SARS eradicated is that it was too easy, this is a good place to be in. We don't get many "wins" against infectious diseases, so let's seize this one. We can only hope that future outbreaks will be as easy to eradicate.

\section{Acknowledgement}

The author is grateful to Kate Fleming for technical discussions. The author is supported by an NSERC Discovery Grant. For citation purposes, please note that the question mark in "Smith?" is part of the author's name.

\section{References}

1. Dowdle WR (1998) The principles of disease elimination and eradication. Bulletin of the World Health Organization 76(2): 22-25.

2. Miller M, Barrett S, Henderson DA (2006) Control and eradication. In: Jamison DT, Breman JG, Measham AR, et al., eds Disease Control Priorities in Developing Countries. Washington (DC): The International Bank for Reconstruction and Development / The World Bank. Chapter 62.

3. Heymann DL (2006) Control, elimination, eradication and re-emergence of infectious diseases: getting the message right. Bulletin of the World Health Organization 84(2): 82.

4. Alyward B, Hennessey KA, Zagario N, Olive J M, Cochi S (2000) When Is a Disease Eradicable? 100 Years of Lessons Learned. American Journal of Public Health 90(10): 1515-1520.

5. Morens DM, Holmes EC, Davis AS, Taunbenberger JK (2011) Global Rinderpest Eradication: Lessons Learned and Why Humans Should Celebrate Too. J Infect Dis 204(4): 502-505.

6. Browne C, Smith? RJ, Bourouiba L (2015) From regional pulse vaccination to global disease eradication: insights from a mathematical model of Poliomyelitis. Journal of Mathematical Biology 71(1): 215-253.

7. Kealey AD, Smith? RJ (2010) Neglected Tropical Diseases: Infection, Modeling, and Control. J Health Care Poor Underserved 21(1): 53-69.

8. Barry M (2007) The Tail End of Guinea Worm-Global Eradication without a Drug or a Vaccine. New England Journal of Medicine 356(25): 2561-2564.

9. Losos J (1998) Report of the work group on viral diseases. In: Goodman RA, et al. (Eds.), Global disease elimination and eradication as public health strategies. Bull World Health Organ 76(Suppl 2): 94-102.

10. Fenner F, Henderson DA, Arita I, Jezek Z, Ladnyi ID (1988) Smallpox and its Eradication. Geneva, Switzerland: World Health Organization 6: 1371-1409.

11. Simon V, Ho DD, Karim QA (2006) HIV/AIDS epidemiology, pathogenesis, prevention, and treatment. The Lancet 368(9534): 489-504.

12. (2005) World Health Organization and UNICEF. World Malaria Report 2005 .

13. Hayes EB, Komar N, Nasci RS, Montgomery SP, O’Leary DR, et al. (2005) Epidemiology and transmission dynamics of West Nile virus disease. Emerging infectious diseases. 11(8): 1167-1173. 
14. Mackenzie JS, Drury P, Ellis A, Grein T, Leitmeyer KC, et al. (2004) The WHO response to SARS and preparations for the future. In: Knobler $S$, et al. (Eds.), Institute of Medicine (US) Forum on Microbial Threats; (2004) Learning from SARS: Preparing for the Next Disease Outbreak: Workshop Summary. National Academies Press, Washington, DC, USA

15. Reilly B, Van Herp M, Sermand D, Dentico N (2003) SARS and Carlo Urbani. N Engl J Med 348(20): 1951-1952.

16. Heymann DL (2004) The international response to the outbreak of SARS in 2003. Philosophical Transactions of the Royal Society of London B Biological Sciences 359(1447): 1127-1129.

17. Zhong NS, Zheng BJ, Li YM, Poon LL, Xie ZH, et al. (2003) Epidemiology and cause of severe acute respiratory syndrome (SARS) in Guangdong, People's Republic of China, in February, 2003. The Lancet 362(9393): 1353-1358

18. Lipsitch M, Cohen T, Cooper B, Robins JM, Ma S, et al. (2003) Transmission dynamics and control of severe acute respiratory syndrome. Science 300(5627): 1966-1970.

19. SM Poutanen, DE Low, B Henry, Finkelstein S, Rose D, et al. (2003) Identification of severe acute respiratory syndrome in Canada. $\mathrm{N}$ Engl Med 348(2): 1995-2005.

20. Wang MD, Jolly AM (2004) Changing virulence of the SARS virus: The epidemiological evidence. Bulletin of the World Health Organization 82(7): 547-548.

21. Xu R (2013) Chance missed, but still there! Memoirs at the 10th anniversary of 2003 SARS outbreak. Journal of thoracic disease 5(Suppl 2): S90-S93.

22. Dwosh HA, Hong HH, Austgarden D, Herman S, Schabas R (2003) Identification and containment of an outbreak of SARS in a community hospital. Canadian Medical Association Journal. 168(11): 1415 -1420.
23. Rello J, Rodrguez A, Ibanez P, Socias L, Cebrian J, et al. (2009). Intensive care adult patients with severe respiratory failure caused by Influenza A (H1N1) v in Spain. Critical care 13(5): R148.

24. Chiu WT, Lin PW, Chiou HY, Lee WS, Lee CN, et al. (2005). Infrared thermography to mass-screen suspected SARS patients with fever. Asia Paci c Journal of Public Health 17(1): 26-28.

25. Yang S, Kymissis I (2015) Large scale temperature monitoring system for detection of potential Ebola patient. Proceedings of the 8th ACM International Conference on Pervasive Technologies Related to Assistive Environments, Article 94

26. Becker NG, Glass K, Li Z, Aldis GK (2005) Controlling emerging infectious diseases like SARS. Mathematical Biosciences. 193(2): 205-221.

27. Yen MY, Schwartz J, Wu JS, Hsueh PR (2015) Controlling Middle East Respiratory Syndrome: Lessons Learned from Severe Acute Respiratory Syndrome. Clinical Infectious Diseases 61(11): 1761-1762.

28. Townsend SE, Sumantra IP, Bagus GN, Brum E, Cleaveland S, et al. (2013) Designing programs for eliminating canine rabies from islands: Bali, Indonesia as a case study. PLoS Negl Trop Dis 7(8): e2372.

29. Mickle P (1976) Fear of a great plague. The Trentonian pp.1-7.

30. Ruan S, Wang W, Levin SA (2006) The effect of global travel on the spread of SARS. Mathematical Biosciences and Engineering. 3(1): 205-218.

31. Khetsuriani N, LaMonte Fowlkes A, Oberst S, Pallansch MA (2006) Enterovirus surveillance-United States, 1970-2005. MMWR Surveill Summ 55(8): 1-20.

32. (2003) World Health Organization, Consensus document on the epidemiology of severe acute respiratory syndrome (SARS) pp.46. 